\title{
The effects of pharmacological interventions on quality of life and fatigue in sarcoidosis: a systematic review
}

\author{
Roeland Vis (1) ${ }^{1}$, Ewoudt M.W. van de Garde $\mathbb{1}^{1}$, Jan C. Grutters ${ }^{2,3}$ and \\ Ingrid H.E. Korenromp ${ }^{2}$
}

Affiliations: 'Dept of Clinical Pharmacy, St Antonius Hospital, Nieuwegein, The Netherlands. ${ }^{2}$ Interstitial Lung Diseases Centre of Excellence, Dept of Pulmonology, St Antonius Hospital, Nieuwegein, The Netherlands. ${ }^{3}$ Division of Heart \& Lungs, University Medical Center Utrecht, Utrecht, The Netherlands.

Correspondence: Roeland Vis, Dept of Clinical Pharmacy, St Antonius Hospital, Koekoekslaan 1, 3435 CM Nieuwegein, The Netherlands. E-mail: r.visdantoniusziekenhuis.nl

@ERSpublications

Pharmacological interventions can improve quality of life and fatigue in subgroups of sarcoidosis patients. http://bit.ly/33kjX9L

Cite this article as: Vis R, van de Garde EMW, Grutters JC, et al. The effects of pharmacological interventions on quality of life and fatigue in sarcoidosis: a systematic review. Eur Respir Rev 2020; 29: 190057 [https://doi.org/10.1183/16000617.0057-2019].

\begin{abstract}
Aims: Many sarcoidosis patients experience a reduction in health-related quality of life (HRQoL) and a majority of patients report fatigue. Historically, drug trials in sarcoidosis have focused on changes in chest radiographs, lung function parameters and biomarkers, while HRQoL and fatigue have not been the main outcomes examined. We performed a systematic review of the literature to evaluate the existing evidence on the effects of pharmacological interventions on HRQoL and fatigue outcomes.

Methods: The systematic search was performed in Medline and Embase and yielded 15 records covering seven randomised controlled trials and seven single-arm open label studies, which were included in a qualitative synthesis (the results of one study were included in two publications). 12 studies evaluated immunosuppressive and/or immunomodulatory therapies and two studies evaluated stimulants.

Results: Nine out of the 14 studies observed positive treatment effects from the interventions on HRQoL and/or fatigue, exceeding the minimal important difference. The risk of bias was generally high with only three studies rated as having a low risk of bias. The results suggest a potential for improvement in HRQoL and/or fatigue in patients with active disease who are either untreated or treated but not yet fully stabilised or therapy refractory.

Conclusion: More randomised, double-blind and placebo-controlled trials are needed to expand the evidence base on these important outcome parameters.

\section{Introduction}

Sarcoidosis is a systemic granulomatous disease primarily affecting the lung and lymphatic systems, but which can also present with ocular, skin, heart and nervous system involvement [1]. The immunopathogenesis involves a complex interaction between host and genetic factors and environmental or infectious triggers, resulting in granuloma formation [2]. Corticosteroids are the mainstay of therapy,
\end{abstract}

This article has supplementary material available from err.ersjournals.com

This review is registered on the PROSPERO database with registration number CRD42019120211

Provenance: Submitted article, peer reviewed.

Received: 23 May 2019 | Accepted after revision: 26 Sept 2019

Copyright $\odot$ ERS 2020. This article is open access and distributed under the terms of the Creative Commons Attribution Non-Commercial Licence 4.0. 
with immunomodulatory and cytotoxic drugs as second- and third-line options [3]. Sarcoidosis patients suffer from persistent nonspecific symptoms and experience a reduction in several domains of health-related quality of life (HRQoL) $[4,5]$. Fatigue is reported in up to $70 \%$ of sarcoidosis patients and is an important negative predictor of quality of life $[6,7]$. In a recent international survey, sarcoidosis patients ranked quality of life as the most important treatment outcome for sarcoidosis therapies [8].

Historically, clinical drug trials in sarcoidosis have focused on changes in chest radiographs, lung function parameters and biomarkers, while HRQoL and fatigue have not been the main outcome parameters. We performed a systematic review of the literature to evaluate the existing evidence on the effects of pharmacological interventions on HRQoL and fatigue outcomes.

\section{Methods}

Search strategy

This systematic review was registered on the PROSPERO database (www.crd.york.ac.uk/prospero/ CRD42019120211) and was performed in accordance with the PRISMA-P (Preferred Reporting Items for Systematic Reviews and Meta-Analyses Protocols ) [9]. The completed PRISMA-P checklist is provided in supplementary table S1.

The population under review was adult subjects with sarcoidosis, and we considered any pharmacological intervention to be eligible. The comparator could be a placebo or no comparator, and the outcomes of interest were any HRQoL or fatigue parameter. Both controlled and uncontrolled clinical trials were included.

The systematic search was performed in the electronic databases Medline (using Pubmed) and Embase up to 19 December, 2018. A clinical librarian was consulted for the design of the systematic search and the exact details of this search are provided in supplementary appendix 1 .

\section{Study selection}

An article was considered eligible if it: 1) exclusively evaluated adult sarcoidosis patients; 2) prospectively evaluated the efficacy of any pharmacological intervention on a measurement score of any HRQoL or fatigue instrument; 3) reported quantitative results for changes in HRQoL or fatigue pre- and post-intervention; and 4) was presented in full-text form and in English. Trials in sarcoidosis-associated pulmonary hypertension were excluded as well as retrospective studies, cross-sectional studies, case series and case reports.

The search results were screened for eligibility based on title and abstract by two reviewers (R. Vis and I. Korenramp). Subsequently, full-text articles were evaluated on relevance by the same reviewers. A summary of search results and the individual assessment by both reviewers, as well as consensus score, were documented on a digital spreadsheet. All included articles were assessed for risk of bias at a study level by both reviewers (R. Vis and I. Korenramp) using the Cochrane Collaboration's tool for assessing risk of bias, which covers: sequence generation, allocation concealment, blinding, incomplete outcome data and selective outcome reporting [10]. A judgement as to the possible risk of bias on each of the domains was made from the extracted information and rated as "high risk" or "low risk". In case of insufficient information, the risk of bias was rated as "unclear". For both the screening process and risk of bias assessment, consensus was sought in cases of differences between reviewers. Where disagreements occurred, a third reviewer (E.M.W. van de Garde) was consulted to resolve the disagreement.

\section{Data extraction}

The following data were extracted from all included studies: main author's last name; year of publication; study design; patient characteristics and number of participants; indication for treatment; intervention and comparator; other systemic therapies; primary and secondary outcomes; measurement scores of HRQoL and/or fatigue and changes in HRQoL and/or fatigue. Instruments on general HRQoL captured were the Short Form-36 Health Survey Questionnaire (SF-36); World Health Organization Quality of Life 100; World Health Organization Quality of Life 100 short (brief) version; St George's Respiratory Questionnaire (SGRQ); Sarcoidosis Health Questionnaire (SHQ); Kings College Questionnaire (KCQ) or Kings Sarcoidosis Questionnaire (KSQ); Sarcoidosis Assessment Tool (SAT) and Patient Global Assessment (PGA). Instruments on fatigue included Fatigue Assessment Scale (FAS), Functional Assessment of Chronic Illness Therapy Fatigue (FACIT-F) and the Checklist Individual Strength (CIS). Studies reporting organ-specific HRQoL instruments (e.g. Skindex skin disease score) were excluded.

\section{Results}

\section{Search results}

The search strategy identified 417 records through Medline and 210 records through Embase. After the removal of duplicates, 524 records were screened of which 460 were excluded because they did not fit the 


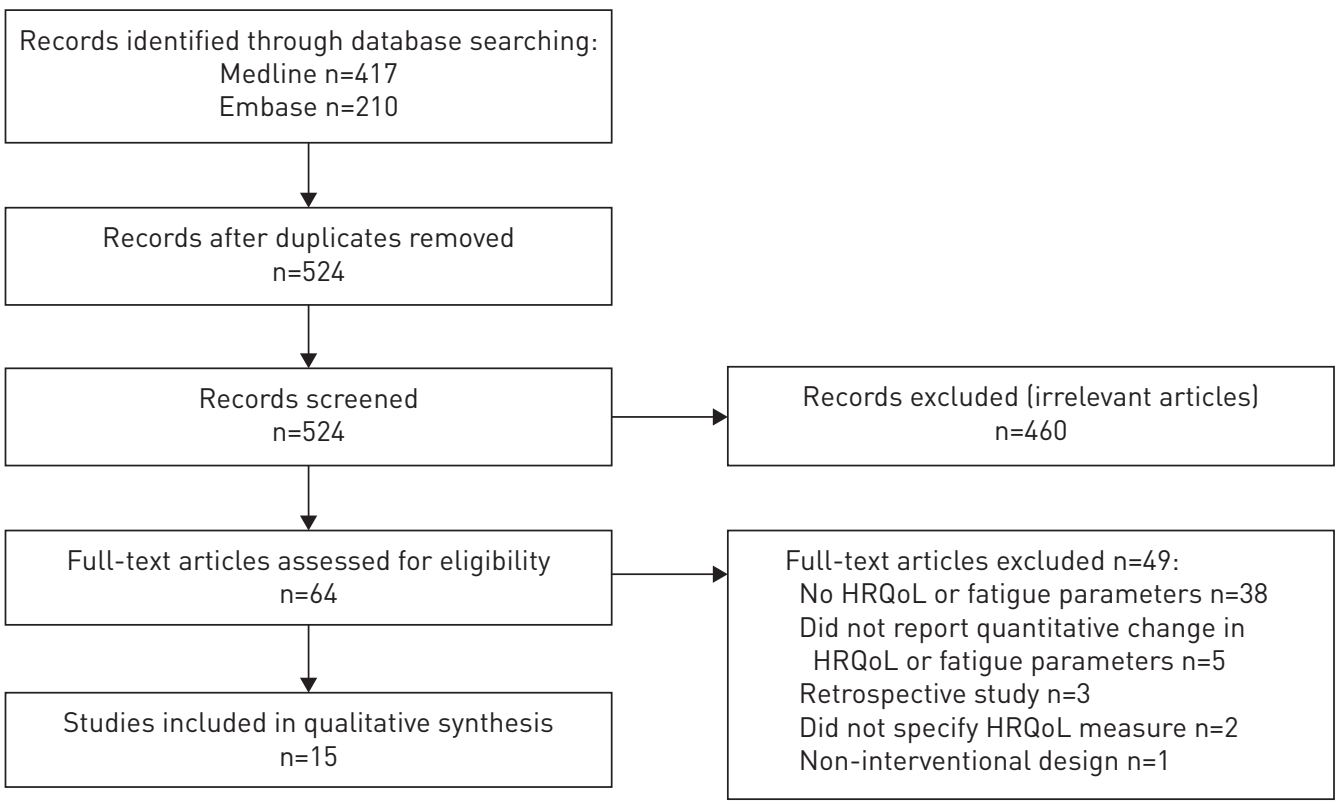

FIGURE 1 Selection process: PRISMA 2009 flow diagram. HRQoL: health-related quality of life.

\section{TABLE 1 Overview of outcomes and selected questionnaires as reported in the included studies}

Outcome Questionnaire

$\begin{array}{ccc}\text { DRQoL } & \text { SF-36 } & \text { 8 domains } \\ & \text { health, physical functioning, role emotional, role } \\ \text { physical, social functioning, vitality } \\ 2 \text { composite scores: MCS, PCS }\end{array}$

$\begin{array}{cccc}\text { HRQoL } & \text { SGRQ } & \text { 3 domains: symptoms, activity, impact } \\ \text { Total score } & \text { of } 50 \\ \text { HRQoL } & \text { SHQ } & \begin{array}{c}3 \text { domains: daily functioning, physical } \\ \text { functioning, emotional functioning } \\ \text { Total score }\end{array} & 1-7 \\ \text { HRQoL } & \text { KSQ } & \begin{array}{c}5 \text { domains: general health status, lung, } \\ \text { medication, skin, eyes }\end{array} & 0-100 \\ \text { HRQoL } & \text { PGA } & \text { Visual analogue scale } & 0-100\end{array}$

Fatigue

FAS

Total score

FACIT-F

Total score
$10-50$

Score range

$0-100$

Corrected to a

of 50

of 50

$1-7$

0-52
Minimal

important

difference

\footnotetext{
HRQoL: health-related quality of life; SF-36: Short Form-36 Health Survey Questionnaire; MCS: Mental Component score; PCS: Physical Component score; SGRQ: St George's Respiratory Questionnaire; SHQ: Sarcoidosis Health Questionnaire; KSQ: Kings Sarcoidosis Questionnaire; PGA: Patient Global Assessment; FAS: Fatigue Assessment Scale; FACIT-F: Functional Assessment of Chronic Illness Therapy Fatigue.
} 
TABLE 2 Summary of data from included studies

\begin{tabular}{|c|c|c|c|c|c|c|}
\hline First author [ref.] & $\begin{array}{l}\text { Study } \\
\text { design }\end{array}$ & $\begin{array}{l}\text { Patients }(n) \text { and } \\
\text { characteristics }\end{array}$ & Intervention & $\begin{array}{l}\text { Other systemic } \\
\text { therapy }\end{array}$ & $\begin{array}{l}\text { Primary } \\
\text { outcomes }\end{array}$ & $\begin{array}{l}\text { Secondary } \\
\text { outcomes }\end{array}$ \\
\hline \multicolumn{7}{|l|}{$\begin{array}{l}\text { Anti-TNF- } \alpha \text { and } \\
\text { anti-IL-12 and }-23 \\
\text { therapy }\end{array}$} \\
\hline UTz [11] & $\begin{array}{l}\text { Open } \\
\text { label }\end{array}$ & $\begin{array}{l}\text { Pulmonary sarcoidosis } \\
\text { with progressive } \\
\text { infiltrates or worsening } \\
\text { pulmonary function } \\
\text { (n=17) }\end{array}$ & $\begin{array}{l}\text { Etanercept } 25 \mathrm{mg} \\
\text { s.c.; twice weekly } \\
\text { for } 12 \text { months }\end{array}$ & $\begin{array}{c}\text { No } \\
\text { immunosuppressive } \\
\text { therapy in the past } \\
3 \text { months }\end{array}$ & $\begin{array}{l}\text { Pulmonary } \\
\text { function, chest } \\
\text { radiograph, } \\
\text { dyspnoea }\end{array}$ & $\begin{array}{l}\text { HRoQL } \\
\text { (SF-36) }\end{array}$ \\
\hline BAUGHMAN $[12,13]$ & $\mathrm{RCT}$ & $\begin{array}{l}\text { Chronic pulmonary } \\
\text { sarcoidosis with FVC } \\
\geqslant 50 \% \text { and } \leqslant 85 \% \\
\text { (n=138) } \\
\text { Subset analysis: } \\
\text { chronic cutaneous } \\
\text { sarcoidosis ( } n=17 \text { ) }\end{array}$ & $\begin{array}{c}\text { Infliximab } \\
3 / 5{\mathrm{mg} \cdot \mathrm{kg}^{-1} \text { i.v.; at }} \\
\text { weeks } 0,2,6,12 \\
18,24 . \\
\text { Placebo }\end{array}$ & $\begin{array}{c}\geqslant 10 \text { mg prednisone or } \\
\text { one or more } \\
\text { immunosuppressants } \\
\text { for } \geqslant 3 \text { months prior to } \\
\text { screening, stable } \\
\text { dosed } \geqslant 1 \text { month prior } \\
\text { to screening } \\
\text { Background } \\
\text { medication stable } \\
\text { during study }\end{array}$ & $\begin{array}{c}\text { Pulmonary } \\
\text { function (FVC) }\end{array}$ & $\begin{array}{l}\text { HRQoL } \\
\text { (SGRQ, } \\
\text { SF-36) }\end{array}$ \\
\hline ERCKENS [14] & $\begin{array}{l}\text { Open } \\
\text { label }\end{array}$ & $\begin{array}{l}\text { Sarcoidosis with } \\
\text { refractory chronic } \\
\text { uveitis, non-responsive } \\
\text { to prednisone and } \\
\text { methotrexate }(n=26)\end{array}$ & $\begin{array}{c}\text { Adalimumab } \\
40 \text { mg s.c.; weekly } \\
\text { for a minimum of } \\
6 \text { months }\end{array}$ & $\begin{array}{l}\text { Prior to study } 100 \% \text { of } \\
\text { patients treated with } \\
\text { oral prednisone } \\
20-60 \text { mg with } \\
\text { methotrexate added if } \\
\text { required } \\
\text { Background } \\
\text { medication was } \\
\text { tapered during study }\end{array}$ & $\begin{array}{c}\text { Uveitis } \\
\text { manifestations }\end{array}$ & $\begin{array}{l}\text { Chest } \\
\text { radiograph, } \\
\text { pulmonary } \\
\text { function, } \\
\text { fatigue } \\
\text { (FAS) }\end{array}$ \\
\hline MILMAN [15] & $\begin{array}{l}\text { Open } \\
\text { label }\end{array}$ & $\begin{array}{l}\text { Intrathoracic }(90 \%) \text { and } \\
\text { extrathoracic }(40 \%) \\
\text { sarcoidosis } \\
\text { non-responsive to } \\
\text { systemic } \\
\text { immunosuppressants; } \\
\text { FDG-PET uptake }(n=10)\end{array}$ & $\begin{array}{l}\text { Adalimumab } \\
40 \text { mg s.c.; } \\
\text { bi-weekly for } \\
24 \text { weeks }\end{array}$ & $\begin{array}{c}\text { Prednisolone } 5-10 \mathrm{mg} \\
\text { daily and/or } \\
\text { methotrexate } \\
10-15 \mathrm{mg} \text { weekly } \\
\text { Stable dosed during } \\
\text { study }\end{array}$ & $\begin{array}{c}\text { FDG-PET } \\
\text { uptake, HRQoL } \\
\text { (SF-36) }\end{array}$ & $\begin{array}{l}\text { Pulmonary } \\
\text { function }\end{array}$ \\
\hline Judson [17] & $\mathrm{RCT}$ & $\begin{array}{l}\text { Chronic pulmonary and/ } \\
\text { or cutaneous } \\
\text { sarcoidosis, FVC } \\
45-80 \% \text {, dyspnoea } \\
\text { (n=173) }\end{array}$ & $\begin{array}{l}\text { Ustekinumab } \\
180 \text { mg s.c. at } \\
\text { week } 0 \text { followed by } \\
90 \text { mg s.c. at } \\
\text { weeks } 8,16,24 . \\
\text { Golimumab } \\
200 \text { mg s.c. at } \\
\text { week } 0 \text { followed by } \\
100 \text { mg every } \\
4 \text { weeks to week } \\
24 \text { Placebo }\end{array}$ & $\begin{array}{l}\text { Systemic treatment } \\
\text { with } 10-25 \text { mg } \\
\text { prednisone equivalent } \\
\text { and/or } \geqslant 1 \\
\text { immunomodulator for } \\
\geqslant 3 \text { months with a } \\
\text { stable dose for } \\
\geqslant 4 \text { weeks prior to } \\
\text { screening. Baseline } \\
\text { medication tapered in } \\
\text { second half of the } \\
\text { study }\end{array}$ & $\begin{array}{c}\text { Pulmonary } \\
\text { function (FVC) }\end{array}$ & $\begin{array}{l}\text { HRQoL } \\
\text { (SGRQ, } \\
\text { SF-36, SAT), } \\
\text { fatigue } \\
\text { (FAS) }\end{array}$ \\
\hline
\end{tabular}


TABLE 2 Continued

\begin{tabular}{|c|c|c|c|c|c|c|}
\hline First author [ref.] & $\begin{array}{l}\text { Study } \\
\text { design }\end{array}$ & $\begin{array}{l}\text { Patients }(n) \text { and } \\
\text { characteristics }\end{array}$ & Intervention & $\begin{array}{l}\text { Other systemic } \\
\text { therapy }\end{array}$ & $\begin{array}{l}\text { Primary } \\
\text { outcomes }\end{array}$ & $\begin{array}{l}\text { Secondary } \\
\text { outcomes }\end{array}$ \\
\hline VoRSELAARS [18] & $\begin{array}{l}\text { Open } \\
\text { label }\end{array}$ & $\begin{array}{l}\text { Active, chronic and } \\
\text { severe sarcoidosis, } \\
\text { refractory to first- and } \\
\text { second-line treatment } \\
\qquad(n=56)\end{array}$ & $\begin{array}{c}\text { Infliximab } \\
5 \mathrm{mg} \cdot \mathrm{kg}^{-1} \text { i.v. at } \\
\text { weeks } 0 \text { and } 2 \text {, } \\
\text { subsequently every } \\
4 \text { weeks totalling } \\
6 \text { months }\end{array}$ & $\begin{array}{c}>90 \% \text { of patients had } \\
\text { used corticosteroids } \\
\text { and methotrexate prior } \\
\text { to the study; } 34 \% \text { of } \\
\text { patients used } \\
\text { prednisone during the } \\
\text { study } \\
\text { Prednisone dose was } \\
\text { tapered during the } \\
\text { study }\end{array}$ & $\begin{array}{l}\text { Functional } \\
\text { response } \\
\text { including } \\
\text { pulmonary } \\
\text { function }\end{array}$ & $\begin{array}{l}\text { HRQoL } \\
\text { (SF-36, } \\
\text { PGA) }\end{array}$ \\
\hline \multicolumn{7}{|l|}{$\begin{array}{l}\text { Corticosteroids and } \\
\text { corticotropin }\end{array}$} \\
\hline AggarWAL [19] & $\begin{array}{l}\text { Open } \\
\text { label }\end{array}$ & $\begin{array}{l}\text { Newly diagnosed, } \\
\text { symptomatic pulmonary } \\
\text { sarcoidosis ( } n=51)\end{array}$ & $\begin{array}{l}\text { Prednisolone } \\
0.75 \mathrm{mg} \cdot \mathrm{kg}^{-1} \text { orally } \\
\text { daily for } 1 \text { month; } \\
\text { subsequently } \\
\text { tapered and } \\
\text { stopped for a total } \\
\text { of } 6 \text { months }\end{array}$ & No previous treatment & Fatigue (FAS) & $\begin{array}{l}\text { HRQoL } \\
(\mathrm{SHQ})\end{array}$ \\
\hline BAUGHMAN [20] & RCT & $\begin{array}{c}\text { Chronic pulmonary } \\
\text { sarcoidosis, pulmonary } \\
\text { deterioration in the past } \\
\text { year }(n=16)\end{array}$ & $\begin{array}{l}\mathrm{RCI} 80 \text { units s.c. } \\
\text { daily during } \\
10 \text { days; followed } \\
\text { by } 40 \text { or } 80 \text { units } \\
\mathrm{RCl} \text { s.c. twice } \\
\text { weekly during } \\
22 \text { weeks. } \\
\mathrm{RCl} \text { used as } \\
\text { steroid-sparing } \\
\text { agent }\end{array}$ & $\begin{array}{c}\geqslant 3 \text { months stable dose } \\
\text { of } \geqslant 5 \text { mg prednisone } \\
\text { equivalent, } \\
\text { subsequently tapered } \\
\text { during study }\end{array}$ & $\begin{array}{l}\text { Prednisone } \\
\text { sparing }\end{array}$ & $\begin{array}{l}\text { Pulmonary } \\
\text { function, } \\
\text { chest } \\
\text { radiograph, } \\
\text { HRQoL } \\
\text { (KSQ, } \\
\text { SGRQ), } \\
\text { fatigue } \\
\text { (FAS) }\end{array}$ \\
\hline \multicolumn{7}{|c|}{$\begin{array}{l}\text { Other } \\
\text { immunosuppressive } \\
\text { and/or } \\
\text { immunomodulating } \\
\text { therapies }\end{array}$} \\
\hline HEIJ [22] & $\mathrm{RCT}$ & $\begin{array}{l}\text { Sarcoidosis with small } \\
\text { fibre neuropathy; } 86 \% \\
\text { pulmonary involvement } \\
\qquad(\mathrm{n}=22)\end{array}$ & $\begin{array}{l}\text { ARA } 2902 \text { mg i.v.; } \\
\text { three times weekly } \\
\text { during } 4 \text { weeks. } \\
\text { Placebo }\end{array}$ & $\begin{array}{c}\text { Oral corticosteroids in } \\
6 \text { out of } 22 \text { patients, } \\
\text { other systemic } \\
\text { anti-inflammatory } \\
\text { drugs in } 3 \text { out of } 22 \\
\text { patients } \\
\text { Stable dosed during } \\
\text { study }\end{array}$ & $\begin{array}{c}\text { Pain (SF-36), } \\
\text { neuropathic } \\
\text { symptoms, } \\
\text { HRQoL } \\
\text { (SF-36), } \\
\text { fatigue (FAS) }\end{array}$ & - \\
\hline Drake [23] & $\begin{array}{l}\text { Open } \\
\text { label }\end{array}$ & $\begin{array}{l}\text { Chronic pulmonary } \\
\text { sarcoidosis, FVC } \\
45-80 \%(n=15)\end{array}$ & $\begin{array}{l}\text { Broad-spectrum } \\
\text { antimycobacterial } \\
\text { therapy (CLEAR } \\
\text { regimen) for } \\
8 \text { weeks }\end{array}$ & $\begin{array}{l}47 \% \text { of patients } \\
\text { received concomitant } \\
\text { corticosteroids (range } \\
3.75-30 \text { mg daily) and/ } \\
\text { or immunomodulators } \\
\text { All therapies were } \\
\text { stable dosed for } \\
\geqslant 6 \text { months }\end{array}$ & $\begin{array}{c}\text { Pulmonary } \\
\text { function (FVC) }\end{array}$ & $\begin{array}{l}\text { HRQoL } \\
\text { (SGRQ) }\end{array}$ \\
\hline
\end{tabular}




\begin{tabular}{|c|c|c|c|c|c|c|}
\hline \multicolumn{7}{|l|}{ Stimulants } \\
\hline LOWER [24] & $\begin{array}{c}\mathrm{RCT} ; \\
\text { crossover }\end{array}$ & $\begin{array}{l}\text { Pulmonary sarcoidosis } \\
\text { for > } 2 \text { years; with } \\
\text { chronic fatigue }(n=10)\end{array}$ & $\begin{array}{c}\text { d-MPH } 5 \text { mg } \\
\text { orally; twice daily } \\
\text { during } 2 \times 8 \text { weeks. } \\
\text { Placebo }\end{array}$ & $\begin{array}{c}100 \% \text { of patients } \\
\text { received } \geqslant 1 \\
\text { immunosuppressive } \\
\text { and/or } \\
\text { immunomodulatory } \\
\text { agents. } \\
\text { Stable dosed during } \\
\text { study }\end{array}$ & $\begin{array}{c}\text { Fatigue } \\
\text { (FACIT-F, FAS) }\end{array}$ & $\begin{array}{l}\text { HRQoL } \\
\text { (SGRQ) }\end{array}$ \\
\hline LoWER [25] & $\begin{array}{c}\text { RCT; } \\
\text { crossover }\end{array}$ & $\begin{array}{l}\text { Pulmonary sarcoidosis } \\
\text { with persistent fatigue } \\
\text { despite stable systemic } \\
\text { treatment ( } n=15)\end{array}$ & $\begin{array}{l}\text { Armodafinil } 150 \text { to } \\
250 \text { mg orally; } \\
\text { daily during } \\
2 \times 8 \text { weeks. } \\
\text { Placebo }\end{array}$ & $\begin{array}{c}100 \% \text { of patients } \\
\text { received } \geqslant 1 \\
\text { immunosuppressive } \\
\text { and/or } \\
\text { immunomodulatory } \\
\text { agents } \\
\text { Stable dosed for } \\
\geqslant 3 \text { months prior to } \\
\text { study and stable dosed } \\
\text { during study }\end{array}$ & $\begin{array}{c}\text { Fatigue } \\
\text { (FACIT-F, FAS) }\end{array}$ & $\begin{array}{l}\text { HRQoL } \\
\text { (SF-36, } \\
\text { SHQ) }\end{array}$ \\
\hline
\end{tabular}

TNF: tumour necrosis factor; IL: interleukin; HRQoL: health-related quality of life; RCT: randomised controlled trial; FVC: forced vital capacity; SGRQ: St George's Respiratory Questionnaire; SF-36: Short Form-36 Health Survey Questionnaire; FAS: Fatigue Assessment Scale; FDG: fluorodeoxyglucose; PET: positron emission tomography; SHQ: Sarcoidosis Health Questionnaire; SAT: Sarcoidosis Assessment Tool; PGA: Patient Global Assessment; RCI: repository corticotropin; KSQ: Kings Sarcoidosis Questionnaire; CLEAR: concomitant levofloxacin, ethambutol, azithromycin, and rifampin: levofloxacin, $500 \mathrm{mg}$ orally, daily+ethambutol $15 \mathrm{mg} \cdot \mathrm{kg}^{-1}$ orally, daily+azithromycin $250 \mathrm{mg}$ orally, daily+rifampin $10 \mathrm{mg} \cdot \mathrm{kg}^{-1}$ orally, daily or rifabutin, $300 \mathrm{mg}$ orally, daily; d-MPH: dexmethylphenidate; FACIT-F: Functional Assessment of Chronic Illness Therapy Fatigue.

selection criteria. The 64 remaining full-text manuscripts were assessed and 15 manuscripts published between 2003 and 2017 were considered eligible. The PRISMA 2009 flow diagram of the screening process is depicted in figure 1.

\section{Characteristics of eligible trials}

A total of 15 records corresponding to 14 unique clinical studies involving a cumulative total of 575 sarcoidosis patients was considered suitable for a qualitative analysis (tables 1-4) [11-25]. A meta-analysis of data was not possible due to the heterogeneity of study designs, patient characteristics, interventions and outcome parameters.

Seven studies were randomised controlled trials, and seven were single-arm, open label studies. In 11 out of 14 studies, sarcoidosis patients with predominantly pulmonary involvement were included, with treatment status ranging from newly diagnosed, untreated disease to chronic, refractory sarcoidosis. Three other studies included patients with chronic uveitis, cutaneous sarcoidosis or small fibre neuropathy, respectively.

12 out of 14 studies evaluated immunosuppressive and/or immunomodulatory therapies: in six studies the intervention consisted of anti-tumour necrosis factor (TNF)- $\alpha$ therapy (adalimumab, etanercept or infliximab), one study evaluated anti-TNF- $\alpha$ and anti-interleukin (IL)-12 and -23 therapy (golimumab and ustekinumab), and thalidomide, prednisolone or repository corticotropin (RCI) were the respective interventions in three other studies. One study evaluated ARA 290, a peptide with anti-inflammatory and tissue protective properties, and one evaluated broad-spectrum antimycobacterial therapy. Finally, in two out of 14 studies the intervention consisted of the stimulants dexmethylphenidate hydrochloride (d-MPH) and armodafinil, respectively.

In 13 of the 14 studies, HRQoL outcome parameters were reported. The SF-36 was reported in eight studies and was the most frequently used HRQoL outcome parameter, followed by the SGRQ which was reported in five studies. Other studies reported the SHQ, the KSQ and the PGA. Fatigue outcome parameters were reported in seven out of 14 studies and always involved the FAS and/or FACIT-F. 
TABLE 3 Summary of included study results: health-related quality of life (HRQoL)

First author [ref.]
Intervention

Infliximab

BAUGHMAN $[12,13]$

MILMAN [15]

\section{Corticosteroids and corticotropin}

\section{Anti-TNF- $\alpha$ and anti-IL-12 and -23 therapy \\ UTz [11]}

PARISER [16]

JUDSON [17]

VorselaARS [18]

AggarWal [19]

Adalimumab

Adalimumab

Ustekinumab

Golimumab

Infliximab

Yes

Prednisolone

Yes

Baughman [20]

$\mathrm{RCl}$

No

Yes

No

\section{Evidence of}

treatment

effect
Effect: HRQoL

Overall risk

of bias
No

No

No

(1)

\pm 2.790 (placebo); $-6.86 \pm 2.921$ (golimumab; $p=0.374$ );

$$
-4.25 \pm 2.662 \text { (ustekinumab; } p=0.073 \text { ) }
$$

No improvements in treatment arms relative to placebo on SF-36 or SAT

Improvement on SF-36 physical functioning: baseline SF-36 PF was 40.6 and increased by 8.2 ( $p=0.009$ )

Sign improvement in health status: baseline PGA was 61.0 and decreased (improved) by 14.6 ( $p<0.0001$ )

Improvement in HRQoL: SHQ daily functioning improved from 4.85 (4.00-5.31) to 5.31 (4.62-5.85); $p=0.003$

$\mathrm{SHQ}$ physical functioning improved from 4.67 (4.00-5.17) to 5.33 (4.67-5.67); $p=0.007$

SHQ emotional functioning improved from 4.80 (3.90$5.50)$ to $5.30(4.90-5.90) ; p=0.001$

SHQ total score improved from $4.83(4.21-5.41)$ to 5.28 (4.59-5.83); $p<0.001$

Improvement in KSQ general health status: increase from 49.8 (15.9-70.9) to 54.3 (31.7-100) (week 7 versus baseline; $p=0.0043$ ) to 58.1 (23.8-100) (week 24 versus baseline; $p=0.0084)$.

Improvement in KSQ lung score: increase from 42.8 (22.3-61.0) to 54.4 (33.6-100) (week 7 versus baseline; $\mathrm{p}=0.0067)$ to 49.6 (37.2-100) (week 24 versus baseline; $\mathrm{NS})$

No sign change in SGRQ total score: 51.49 (21.89-77.21) to 54.88 (34.1-70.31; week 7) to 54.13 (25.4-71.1; week 24).

No significant differences on other SGRQ scales
High

Unclear

High

RCT phase: low Open label phase: high

Unclear High

High

High 
TABLE 3 Continued

First author [ref.]
Intervention
Effect: HRQoL
Overall risk

of bias

effect

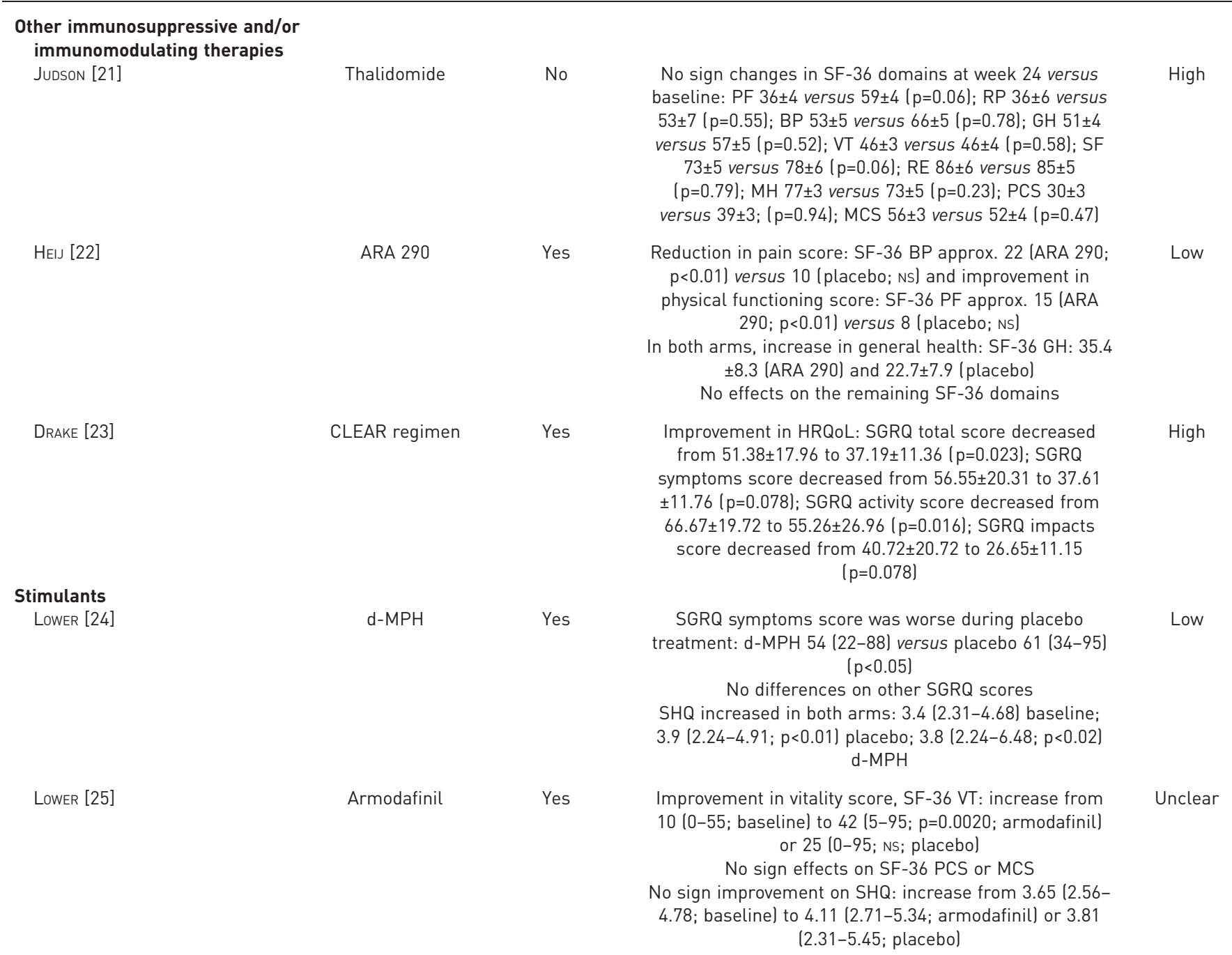

TNF: tumour necrosis factor; IL: interleukin; NS: nonsignificant; SF-36: Short Form-36 Health Survey Questionnaire; BP: bodily pain; MCS: Mental Component score; SGRQ: St George's Respiratory Questionnaire; PCS: Physical Component score; RCT: randomised controlled trial; SHQ: Sarcoidosis Health Questionnaire; SAT: Sarcoidosis Assessment Tool; PGA: patient global assessment; KSQ: Kings Sarcoidosis Questionnaire; RCl: repository corticotropin; PF: physical functioning; RP: role physical; GH: general health; VT: vitality; SF: social functioning; RE: role emotional; $\mathrm{MH}$ : mental health; CLEAR: concomitant levofloxacin, ethambutol, azithromycin, and rifampin; d-MPH: dexmethylphenidate.

\section{Summary of immunosuppressive and/or immunomodulating therapies \\ Etanercept}

In the open label, single-arm, phase-2 trial of UTZ et al. [11] in 17 progressive stage II or III pulmonary sarcoidosis patients, etanercept $25 \mathrm{mg}$ subcutaneously twice weekly had no significant effect on the SF-36 Physical Component Scores (PCS) and Mental Component Scores (MCS). The study was terminated due to excessive treatment failures based on clinical outcomes.

\section{Infliximab}

A phase-2, randomised, double-blind, placebo-controlled study in 138 chronic pulmonary sarcoidosis patients by BAUGHMAN et al. [12] evaluated infliximab 3 and $5 \mathrm{mg} \cdot \mathrm{kg}^{-1}$ at weeks $0,2,6,12,18$ and 24 . Patients were on a stable dose of immunosuppressants before study entry. No significant effect on SGRQ total score was observed. In a subset analysis of 17 patients with chronic cutaneous sarcoidosis, no significant effect was observed on SF-36 PCS and MCS [13]. 
TABLE 4 Summary of included study results: fatigue

First author [ref.]
Intervention

\author{
Evidence of \\ treatment \\ effect
}

Effect: fatigue
Overall

risk of

bias

\section{Anti-TNF- $\alpha$ and IL-12 and -23 therapy \\ ERCKENS [14]}

JuDSON [17]

Corticosteroids and corticotropin AggarWal [19]

BAUghman [20]

\section{Other immunosuppressive and/ or immunomodulating therapies} HEIJ [22]

\section{Stimulants}

LOWER [24]
Adalimumab Yes

Ustekinumab

Golimumab

Prednisolone

ARA 290

No

Yes

d-MPH

Yes

In both arms fatigue decreased to a similar extent (NS): FAS $37.9 \pm 2.6$ to $33.3 \pm 2.8$ (ARA 290) and $33.6 \pm 2.3$ to $29.8 \pm 3.3$ (placebo)

Improvement in fatigue in d-MPH treated group: FACIT-F on average 30 ( $p<0.001)$

FACIT-F on average during placebo arm: $24.3 \pm 5.41$ Improvement in fatigue in d-MPH treated group: FAS on average $27(p<0.02)$.

FAS on average during placebo arm: $33.6 \pm 4.43$

Improvement in fatigue: change in FAS score versus baseline for armodafinil versus placebo: $-2.5(-10.2$

to 0.8 ) versus $1.5(-0.1$ to 4.3 ) ( 4 weeks; $p=0.0676$ ) and $-4.5(-11.1$ to 2.1$)$ versus 3.5 (0.0 to 8.0 ) (8 weeks; $p=0.0295$ )

Improvement in fatigue: change in FACIT-F score versus baseline for armodafinil versus placebo: $6(-3.4$ to 14.1$)$ versus $-6(-9.1$ to -1.9$)$ ( 4 weeks; $\mathrm{p}=0.0149)$ and $9(-0.2$ to 17.0$)$ versus $-5(-13.1$ to 1.1) ( 8 weeks; $p=0.0040$ )

TNF: tumour necrosis factor; IL: interleukin; FAS: Fatigue Assessment Scale; RCl: repository corticotropin; NS: nonsignificant; d-MPH: dexmethylphenidate; FACIT-F: Functional Assessment of Chronic Illness Therapy Fatigue.

Significant improvements in HRQoL were observed by VORSELAARS et al. [18] in a single-arm open-label study of infliximab $5 \mathrm{mg} \cdot \mathrm{kg}^{-1}$ every 4 weeks in 56 sarcoidosis patients. Only patients with severe, active, sarcoidosis, unresponsive to first- and second-line treatment, were included. After 26 weeks of therapy, the mean PGA score decreased by $14.6(\mathrm{p}<0.0001)$ and the SF-36 PF score increased by $8.2(\mathrm{p}=0.009)$.

\section{Adalimumab}

Three studies evaluated adalimumab. In a single-arm, open-label study by Milman et al. [15], adalimumab $40 \mathrm{mg}$ was administered bi-weekly in 10 sarcoidosis patients with intrathoracic (90\%) and extrathoracic 
(40\%) involvement. At study entry patients were unresponsive to previous systemic therapy. The observed increase in SF-36 PCS from 34.8 to 38.4 did not reach statistical significance $(\mathrm{p}=0.07)$.

ERCKENs et al. [14] reported another single-arm, open-label study in which adalimumab was administered in a higher dose density of $40 \mathrm{mg}$ every week for 12 months in sarcoidosis patients $(\mathrm{n}=26)$ with refractory uveitis. Fatigue improved significantly with FAS total score decreasing from 31.1 at baseline to 28.5 at 6 months $(\mathrm{p}<0.01)$ and 28.9 at 12 months $(\mathrm{p}<0.01)$.

Finally, a randomised, double-blind, placebo-controlled study by PARISER et al. [16] evaluated adalimumab $40 \mathrm{mg}$ weekly for 12 weeks, followed by an additional 12 weeks of open-label adalimumab. Patients were required to have moderate-to-severe cutaneous sarcoidosis with immunosuppressants either discontinued or reduced to a maximum of $20 \%$ of the baseline dose. In the double-blind treatment phase, HRQoL as measured by the SHQ did not differ significantly between the treatment and the control group. In the open label phase, HRQoL improved with a SHQ score increasing from 4.57 at baseline to 5.06 at week 24 $(\mathrm{p}=0.0029)$ to 5.22 at week $32(\mathrm{p}=0.0015)$ in the treatment arms, exceeding the minimal important difference (MID) of 0.5 .

\section{Ustekinumab and golimumab}

JuDson et al. [17] reported a large, phase 2, randomised, double-blind and placebo-controlled study in which ustekinumab (180 mg at week 0; $90 \mathrm{mg}$ at weeks 8,16 and 24) and golimumab (200 $\mathrm{mg}$ at week 0; $100 \mathrm{mg}$ every 4 weeks through to week 24) were compared. A total of 173 patients were included with chronic pulmonary and/or skin sarcoidosis who were on a stable dose of immunosuppressants before study entry. In the second half of the study, baseline systemic treatment was tapered. No significant effects were observed on HRQoL (SGRQ, SF-36 or SAT) or fatigue (FAS) in any of the treatment arms.

\section{Corticosteroids and corticotropin}

Oral prednisolone starting at a dose of $0.75 \mathrm{mg} \cdot \mathrm{kg}^{-1}$ and subsequently tapering during a total of 6 months significantly improved HRQoL and fatigue. In a single-arm, open label study AGGARwAL et al. [19] reported 51 newly diagnosed, symptomatic and previously untreated pulmonary sarcoidosis patients. All four scores of the SHQ improved significantly, with the SHQ total score increasing from 4.83 to 5.28 $(\mathrm{p}<0.001)$, approaching the MID of 0.5 . FAS total score improved from 24 to 21 ( $\mathrm{p}=0.004)$. Of patients with pre-treatment fatigue (FAS $\geqslant 22), 64 \%$ of patients improved by $>4$ points in FAS score, which was the MID. RCI was also shown to improve HRQoL and fatigue [20].In a single-blind study by BAUGHMAN et al. [20], chronic pulmonary sarcoidosis patients, who were treated with a stable dose corticosteroids were randomised to receive 40 - or 80 -units RCI twice weekly for 22 weeks. The KSQ general health status score significantly improved in the combined RCI group from 49.8 (baseline) to 54.3 (week 7; p=0.0043) to 58.1 (week 24; $\mathrm{p}=0.0084$ ), exceeding the MID of $\geqslant 4$ points. The SGRQ total score did not change significantly: 51.49 (baseline) to 54.88 (week 7) to 54.13 (week 24). The FAS total (fatigue) score significantly improved from 28 (baseline) to 26 (week 7; Ns) to 22 (week 24; p=0.0067), exceeding the MID of $\geqslant 4$ points.

\section{Others}

In an open label, single-arm pilot study by JUDSON et al. [21], thalidomide at a dose of $200{\mathrm{mg} \cdot d a y^{-1}}^{\text {for }}$ 24 weeks was evaluated as a steroid-sparing agent in pulmonary sarcoidosis patients who were on a stable dose corticosteroids. No significant effects were observed on any of the SF-36 subscales.

An open label, single-arm phase I study by DRAKE et al. [23] evaluated the safety and efficacy of a four drug antimycobacterial regimen in 15 chronic pulmonary sarcoidosis patients. Approximately half the patients received concomitant immunosuppressive therapy. The SGRQ scores improved at 8 weeks versus baseline: SGRQ total score decreased with 14 points $(\mathrm{p}=0.023)$; symptoms score with 19 points $(\mathrm{p}=0.078)$; activity score with 11 points $(\mathrm{p}=0.016)$; and impacts score with 14 points $(\mathrm{p}=0.078)$, these changes exceeded the MID of $\geqslant 4$ points.

Finally, Heij et al. [22] evaluated ARA 290 in 22 sarcoidosis patients with small fibre neuropathy and predominant (86\%) pulmonary involvement in a double-blind, placebo-controlled study. Fatigue improved nonsignificantly to a similar extent in both treatment arms. A significant reduction in SF-36 pain score was observed with a change of approximately 22 in the ARA 290-treated group $(p<0.01)$ versus 10 in the placebo-treated group (NS) and a significant improvement in SF-36 physical functioning was seen with a change of approximately 15 (ARA 290; $\mathrm{p}<0.01$ ) versus 8 (placebo; Ns).

\section{Summary of stimulants}

Two double-blind, randomised, placebo-controlled crossover trials by Lower and co-workers [24, 25] evaluated the effect of stimulants on fatigue and HRQoL in pulmonary sarcoidosis patients with chronic fatigue despite systemic maintenance therapy. In 10 patients, d-MPH $5 \mathrm{mg}$ twice daily for 8 weeks 
significantly improved fatigue both on the FACIT-F and FAS scores. The FACIT-F score improved from an average of 24.3 in the placebo arm to $~ 30$ during the d-MPH arm $(\mathrm{p}<0.001$; MID ranges from 3 to 6$)$ and the FAS total score improved from an average of 33.6 in the placebo arm to an average of approximately 27 in the d-MPH arm $(\mathrm{p}<0.02 ; \mathrm{MID} \geqslant 4)$. SGRQ symptom score was lower during d-MPH treatment versus placebo with a score of 54 versus $61(\mathrm{p}<0.05)$, corresponding to a better HRQoL during d-MPH treatment [24].

Armodafinil up to a maximum of $250 \mathrm{mg}$ daily for 8 weeks was evaluated in 15 patients [25]. Armodafinil, but not placebo, improved fatigue on FAS total score: change -2.5 versus 1.5 (4 weeks; $\mathrm{p}=0.0676$ ) and -4.5 versus 3.5 ( 8 weeks; $\mathrm{p}=0.0295$ ), as well as FACIT-F score: change 6 versus -6 ( 4 weeks; $\mathrm{p}=0.0149$ ) and 9 versus -5 ( 8 weeks; $\mathrm{p}=0.0040$ ). For both scores, the effect in the armodafinil treated groups exceeded the MID of four points. Armodafinil, but not placebo, significantly improved fatigue on the SF-36 vitality score: 42 ( 8 weeks) versus 10 (baseline; $\mathrm{p}=0.0020$ ), exceeding the MID that ranges from 7.3 to 11.3.

\section{Risk of bias}

Only three studies were rated as having a low risk for bias, and eight studies were rated as having a high risk for bias, including all seven studies with open label design (supplementary table S2).

\section{Discussion}

This systematic review suggests that there is some evidence for beneficial effects of pharmacological interventions on HRQoL and fatigue for patients with sarcoidosis. Nine out of the 14 included studies observed a positive treatment effect from pharmacological agents, ranging from immunosuppressive and immunomodulatory therapies to stimulants. However, the evidence remains weak with studies showing significant heterogeneity in the included clinical characteristics and treatment status of patients, pharmacological interventions and outcome parameters. Furthermore, the majority of studies involved small numbers of patients and there were only three trials in which the risk for bias was considered low. While the two studies investigating stimulants were designed to include fatigued patients, none of the 12 studies investigating immunosuppressive and immunomodulatory agents were specifically designed to include patients with fatigue or a reduced HRQoL.

HRQoL is a multidimensional construct, consisting of physical, social, mental/emotional and cognitive domains and refers to the extent to which one or more of these domains are affected by a medical condition and its treatment [26]. For patients with sarcoidosis, HRQoL is determined by a complex interplay of biological factors such as immune system dysregulation, constitutional symptoms, fatigue, organ specific involvement, and functional, physical and social limitations [27]. Fatigue is a common symptom of sarcoidosis and there is evidence that it is a more important, negative predictor of quality of life than commonly used clinical parameters such as chest radiographs and lung function tests [7]. In sarcoidosis, as well as in other chronic diseases, there is an apparent link between the release of cytokines such as TNF- $\alpha$ and IL-1 and fatigue $[6,28,29]$. The beneficial effects of immunosuppressive and immunomodulating agents on fatigue in several of the included studies in this review seem to support this inflammatory basis. The improvements in HRQoL following some of the therapies described could be the result of improvements in inflammatory profile, physical symptoms, fatigue and/or pain.

The heterogeneity in treatment effects observed in this review could be explained by the heterogeneity in patient characteristics and treatment strategies in the included studies. First, the patients in these studies differed in duration of disease and treatment status at the time of enrolment. Only one study included newly diagnosed, symptomatic, untreated patients, yielding positive effects from oral corticosteroids on clinical symptoms, HRQoL and fatigue [19]. All other studies included patients with chronic sarcoidosis (up to an average of 10 years duration) who had been pre-treated with one or more line of immunosuppressive and/or immunomodulating therapy, and of whom a majority were receiving systemic treatment at the time of enrolment.

Secondly, the 13 studies which enrolled patients who had been pre-treated with systemic therapies differed in pre-treatment continuation or discontinuation strategies. In the studies of UTZ et al. [11] and PARISER et al. [15], systemic therapies were discontinued 1 to 3 months prior to the studies. The absence of beneficial effects of etanercept in the study by UTZ et al. [11] was to be expected considering the lack of efficacy of etanercept for patients with sarcoidosis and its replacement by other anti-TNF- $\alpha$ therapies such as adalimumab and infliximab [11,30]. However, in the study of PARISER et al. [15], adalimumab was shown to improve both cutaneous lesions and HRQoL [16].

In four other studies, baseline systemic treatment was tapered during the study intervention [14, 18, 20, 21]. In the study by ERCKENS et al. [14], adalimumab was started and prednisone subsequently tapered, yielding improvements in clinical symptoms, disease activity markers and fatigue. VorselaARs et al. [18] studied 
infliximab with subsequent tapering of the prednisone dose, and observed improvements in lung function parameters, disease activity markers and HRQoL. BAUGHMAN et al. [20] tapered the prednisone dose after initiating repository corticotropin. The intervention resulted in improvement in one of the lung function parameters, disease activity marker, HRQoL and fatigue. JUDSON et al. [21] observed a potential prednisone sparing effect from thalidomide, but no significant effect on lung function parameters or HRQoL.

In the remaining seven studies, immunosuppressive and/or immunomodulatory therapies were continued at a stable dose during the study intervention [12, 15, 17, 22-25]. Of particular interest is the absence of beneficial effects on clinical symptoms, HRQoL or fatigue in the two large, placebo-controlled, randomised trials by BAUGHMAN et al. [12] and JUDSON et al. [17] evaluating anti-TNF- $\alpha$, anti-IL-12 and anti-IL-23 therapies that involved 311 out of the total 575 patients included in this review. In these trials, the results on the clinical outcome parameters were negative or of marginal clinical significance. In both these trials, the intervention was added after the patients were documented to be stable on maintenance immunosuppressive and/or immunomodulatory therapy, although the trial by JuDson et al. [17] applied tapering of baseline therapy in the second half of the study (after the primary end-point). It has been suggested that this pre-treatment was responsible for the limited or absent additional benefit of the intervention, and this could also explain the absence of significant improvement on HRQoL and fatigue [31]. This is supported by the study of MiLman et al. [15] in which no additional benefit from adalimumab to stable dosed prednisone and methotrexate was observed on lung function parameters and HRQoL, although it should be noted that the adalimumab dose density was only half of that in the studies by ERCKens et al. [14] and Pariser et al. [16]. In the studies from Heij et al. [22] and Drake et al. [23], however, improvements in both clinical symptoms and HRQoL were observed upon treatment with ARA 290 and a four drug antimycobacterial regimen. Interestingly, in both studies, fewer than half of the patients received concomitant systemic therapy, which could potentially explain why the addition of the study intervention was actually beneficial $[22,23]$.

In the two studies from Lower and co-workers [24, 25] improvements in HRQoL and fatigue were observed after the addition of stimulants to patients receiving concomitant immunosuppressive and/or immunomodulatory agents in a stable dose. These studies differed from the other studies in that the study intervention involved stimulants as opposed to immunosuppressive and/or immunomodulatory therapies.

Considering all the factors mentioned above, it appears that patients who are pre-treated and clinically stabilised with a continued stable dose of immunosuppressive and/or immunomodulating therapy are less likely to benefit from additional lines of therapy. This is supported by the observation that in all five studies of immunosuppressive or immunomodulating agents in the current review where no, or only marginal improvements, were seen on clinical outcomes, no improvements in HRQoL or fatigue were observed $[11,12,15,17,21]$. However, in the seven studies investigating immunosuppressive or immunomodulating agents that did observe significant and meaningful improvements in clinical symptoms, improvements in HRQoL or fatigue were also observed [14, 16, 18, 19, 20, 22, 23]. This suggests that immunosuppressive and immunomodulating agents could improve HRQoL and fatigue in patients with sarcoidosis, as long as there is ongoing activity of disease (based on clinical symptoms and/or disease activity markers), and provided that patients are either untreated or treated but not yet fully stabilised or refractory to therapy. The implication could be that newly diagnosed, untreated patients with active disease who experience fatigue and/or a reduced HRQoL could benefit from immunosuppressive and immunomodulating agents. In case of unacceptable loss of HRQoL with ongoing disease activity despite therapy with first-line agents, there could be benefit in upscaling to second- or third-line agents. However, if patients are clinically stabilised and receiving a stable dose of systemic treatment but still experience reduced HRQoL and/or fatigue, stimulants could potentially be the preferred treatment option.

\begin{tabular}{|c|c|c|c|c|}
\hline & & $\begin{array}{l}\text { Not receiving } \\
\text { immunosuppressive agents }\end{array}$ & $\begin{array}{l}\text { Receiving first-line } \\
\text { immunosuppressive agent }\end{array}$ & $\begin{array}{l}\text { Optimally treated with first- to } \\
\text { third-line immunosuppressive agents }\end{array}$ \\
\hline $\begin{array}{l}\text { Disease } \\
\text { activity } \\
\text { present }\end{array}$ & $\begin{array}{l}\text { Yes } \\
\text { No }\end{array}$ & $\begin{array}{l}\text { Initiate trial of first-line } \\
\text { immunosuppressive agent } \\
\text { Initiate trial of stimulant }\end{array}$ & $\begin{array}{l}\text { Switch to trial of second- or third-line } \\
\text { immunosuppressive agent } \\
\text { Initiate trial of stimulant }\end{array}$ & Initiate trial of stimulant \\
\hline
\end{tabular}


The same might be valid for patients with chronically reduced HRQoL in whom there is no suggestion of ongoing disease activity. A summary of these treatment options in which patients might experience positive changes regarding fatigue and/or HRQoL is provided in table 5.

Another aspect to consider in HRQoL and fatigue in patients with sarcoidosis is the potential of systemic treatment, specifically corticosteroids, to have a negative effect on HRQoL [26]. This review is not able to distinguish disease effects from treatment effects on HRQoL, since only one trial involved newly diagnosed, untreated patients. Three out of four studies in which baseline corticosteroids were tapered during the study intervention showed positive results on HRQoL and fatigue. However, the fact that these patients were often treatment refractory and clinical improvements were also observed during the intervention seems to suggest that these patients were not yet optimally treated. This is supported by the fact that the largest trial included in this review did not show beneficial effects on HRQoL or fatigue from tapering of baseline corticosteroids which was applied in the second half of the trial [17]. Irrespective of the effects from systemic treatment on HRQoL and fatigue, the pharmacological interventions in the studies included in this review have the potential for side-effects, such as corticosteroid-associated weight gain, mandating a risk/benefit evaluation prior to the initiation of therapy.

Although the present review is focused exclusively on pharmacological interventions, non-pharmacological interventions such as exercise programmes have been reported to be beneficial in sarcoidosis-associated fatigue [26].

For patients with sarcoidosis, multiple HRQoL and fatigue questionnaires exist, both generic and disease specific. In the present review, the SF-36, SGRQ and SHQ were the most frequently applied HRQoL instruments, and beneficial effects of pharmacological interventions were observed on all three questionnaires. Only the SHQ is sarcoidosis specific, but all three questionnaires have been validated in patients with interstitial lung disease and have been used in several studies in patients with sarcoidosis [26, 32]. Based on our results, there is no clear preference for any one of these questionnaires to be used in future studies. However, in a number of instances only composite or total scores were reported, which could potentially obscure treatment effects on a specific subscale or domain. It therefore seems preferable to always report the results of all subscales and composite or total scores of a given instrument. For measuring fatigue, all studies used the FAS and two studies used both the FAS and the FACIT-F. The FAS is therefore by far the most frequently used fatigue questionnaire and, furthermore, is sarcoidosis specific.

Overall the evidence base for pharmacological treatment of reduced HRQoL or fatigue in patients with sarcoidosis remains limited. Only six randomised, double-blind, placebo-controlled trials were identified, including two trials that investigated stimulants. Considering that immunosuppressive and immunomodulatory therapies are the mainstay of sarcoidosis treatment, future research efforts should be focused on these interventions. In addition, future studies should focus on newly diagnosed, untreated patients and patients who are refractory to first-line treatment. Future studies should be specifically designed to include patients who are fatigued and/or have a reduced HRQoL. During the design, conduct and reporting of such trials, the criteria as defined in the Consolidated Standards of Reporting Trials (CONSORT) should be followed as in several randomised controlled trials included in this review reporting on these criteria was incomplete [33].

In conclusion, this systematic review suggests beneficial treatment effects of pharmacological interventions on HRQoL and fatigue in subgroups of sarcoidosis patients. More high quality randomised, double-blind and placebo-controlled trials are needed to expand the evidence base on these important outcome parameters.

Acknowledgements: The authors wish to thank Carla Sloof-Enthoven (St Antonius Hospital, Nieuwegein, The Netherlands) for excellent assistance with designing the literature search.

Author contributions: R. Vis, E.M.W. van de Garde, J.C. Grutters and I.H.E. Korenromp were involved in conception and study design. R. Vis and I.H.E. Korenromp completed the literature search and assessed the eligibility of studies for inclusion. R. Vis and I.H.E. Korenromp assessed all included studies for risk for bias. E.M.W. van de Garde and J.C. Grutters contributed to study supervision. R. Vis was responsible for the preparation and writing of the manuscript. All authors revised the article critically for important intellectual content and gave final approval of the version to be published. R. Vis is the guarantor of this review.

Conflict of interest: None declared.

\section{References}

1 Statement on Sarcoidosis. Joint Statement of the American Thoracic Society (ATS), the European Respiratory Society (ERS) and the World Association of Sarcoidosis and Other Granulomatous Disorders (WASOG) adopted 
by the ATS Board of Directors and by the ERS Executive Committee, February 1999. Am J Respir Crit Care Med 1999; 160: 736-755.

2 Spagnolo P, Rossi G, Trisolini R, et al. Pulmonary sarcoidosis. Lancet Respir Med 2018; 6: 389-402.

3 Baughman RP, Grutters JC. New treatment strategies for pulmonary sarcoidosis: antimetabolites, biological drugs, and other treatment approaches. Lancet Respir Med 2015; 3: 813-822.

4 Wirnsberger RM, de Vries J, Wouters EF, et al. Clinical presentation of sarcoidosis in The Netherlands an epidemiological study. Neth J Med 1998; 53: 53-60.

5 Cox CE, Donohue JF, Brown CD, et al. Health-related quality of life of persons with sarcoidosis. Chest 2004; 125: 997-1004.

6 Drent M, Lower EE, De Vries J. Sarcoidosis-associated fatigue. Eur Respir J 2012; 40: $255-263$.

7 Drent M, Marcellis R, Lenssen A, et al. Association between physical functions and quality of life in sarcoidosis. Sarcoidosis Vasc Diffus Lung Dis 2014; 31: 117-128.

8 Boyd J, Baughman RP, Valeyere D, et al. Sarcoidosis treatment and outcomes: what is most important to patients? Eur Respir J 2018; 52: Suppl. 62, PA5219.

9 Moher D, Shamseer L, Clarke M, et al. Preferred reporting items for systematic review and meta-analysis protocols (PRISMA-P) 2015 statement. Syst Rev 2015; 4: 1.

10 Higgins JPT, Altman DG, Gøtzsche PC, et al. The Cochrane Collaboration's tool for assessing risk of bias in randomised trials. BMJ 2011; 343: d5928.

11 Utz JP, Limper AH, Kalra S, et al. Etanercept for the treatment of stage II and III progressive pulmonary sarcoidosis. Chest 2003; 124: 177-185.

12 Baughman RP, Drent M, Kavuru M, et al. Infliximab therapy in patients with chronic sarcoidosis and pulmonary involvement. Am J Respir Crit Care Med 2006; 174: 795-802.

13 Baughman RP, Judson MA, Lower EE, et al. Infliximab for chronic cutaneous sarcoidosis: a subset analysis from a double-blind randomized clinical trial. Sarcoidosis Vasc Diffus Lung Dis 2016; 32: 289-295.

14 Erckens RJ, Mostard RLM, Wijnen PAHM, et al. Adalimumab successful in sarcoidosis patients with refractory chronic non-infectious uveitis. Graefe's Arch Clin Exp Ophthalmol 2012; 250: 713-720.

15 Milman N, Graudal N, Loft A, et al. Effect of the TNF- $\alpha$ inhibitor adalimumab in patients with recalcitrant sarcoidosis: a prospective observational study using FDG-PET. Clin Respir J 2012; 6: 238-247.

16 Pariser RJ, Paul J, Hirano S, et al. A double-blind, randomized, placebo-controlled trial of adalimumab in the treatment of cutaneous sarcoidosis. J Am Acad Dermatol 2013; 68: 765-773.

17 Judson MA, Baughman RP, Costabel U, et al. Safety and efficacy of ustekinumab or golimumab in patients with chronic sarcoidosis. Eur Respir J 2014; 44: 1296-1307.

18 Vorselaars ADM, Crommelin HA, Deneer VHM, et al. Effectiveness of infliximab in refractory FDG PET-positive sarcoidosis. Eur Respir J 2015; 46: 175-185.

19 Aggarwal AN, Sahu KK, Gupta D. Fatigue and health-related quality of life in patients with pulmonary sarcoidosis treated by oral corticosteroids. Sarcoidosis Vasc Diffus Lung Dis 2016; 33: 124-129.

20 Baughman RP, Sweiss N, Keijsers R, et al. Repository corticotropin for chronic pulmonary sarcoidosis. Lung 2017; 195: 313-322.

21 Judson MA, Silvestri J, Hartung C, et al. The effect of thalidomide on corticosteroid-dependent pulmonary sarcoidosis. Sarcoidosis Vasc Diffus Lung Dis 2006; 23: 51-57.

22 Heij L, Niesters M, Swartjes M, et al. Safety and efficacy of ARA 290 in sarcoidosis patients with symptoms of small fiber neuropathy: a randomized, double-blind pilot study. Mol Med 2012; 18: 1430-1436.

23 Drake WP, Richmond BW, Oswald-Richter K, et al. Effects of broad-spectrum antimycobacterial therapy on chronic pulmonary sarcoidosis. Sarcoidosis Vasc Diffus Lung Dis 2013; 30: 201-211.

24 Lower EE, Harman S, Baughman RP. Double-blind, randomized trial of dexmethylphenidate hydrochloride for the treatment of sarcoidosis-associated fatigue. Chest 2008; 133: 1189-1195.

25 Lower EE, Malhotra A, Surdulescu V, et al. Armodafinil for sarcoidosis-associated fatigue: a double-blind, placebo-controlled, crossover trial. J Pain Symptom Manage 2013; 45: 159-169.

26 Judson MA. Quality of life in sarcoidosis. Semin Respir Crit Care Med 2017; 38: 546-558.

27 Victorson DE, Cella D, Grund H, et al. A conceptual model of health-related quality of life in sarcoidosis. Qual Life Res 2014; 23: 89-101.

28 Baydur A, Alavy B, Nawathe A, et al. Fatigue and plasma cytokine concentrations at rest and during exercise in patients with sarcoidosis. Clin Respir J 2011; 5: 156-164.

29 Louati K, Berenbaum F. Fatigue in chronic inflammation - a link to pain pathways. Arthritis Res Ther 2015; 17: $1-10$.

30 Baughman RP, Lower EE, Drent M. Inhibitors of tumor necrosis factor (TNF) in sarcoidosis: who, what, and how to use them. Sarcoidosis Vasc Diffus Lung Dis 2008; 25: 76-89.

31 Moller DR. Negative clinical trials in sarcoidosis: failed therapies or flawed study design? Eur Respir J 2014; 44: 1123-1126.

32 De Vries J, Lower EE, Drent M. Quality of life in sarcoidosis: assessment and management. Semin Respir Crit Care Med 2010; 31: 485-493.

33 Moher D, Hopewell S, Schulz KF, et al. CONSORT 2010 explanation and elaboration: updated guidelines for reporting parallel group randomised trials. BMJ 2010; 340: c869. 